\title{
CTENOCEPHALIDES FELIS FELIS (BOUCHÉ, 1835) E RHIPICEPHALUS (BOOPHILUS) MICROPLUS (CANESTRINI, 1887) EM CAPRINOS E OVINOS NO MUNICÍPIO DE SINOP, MATO GROSSO, BRASIL
}

\author{
M.R. Pereira ${ }^{1}$, G.A.G. Silva ${ }^{1}$, A.S. Maciel$^{2}$, J.A. Galhardo ${ }^{1}$, A.K. Campos ${ }^{1}$ \\ ${ }^{1}$ Universidade Federal de Mato Grosso, Instituto de Ciências da Saúde, Avenida Alexandre Ferronato, 1200, \\ 78550-000, Sinop, MT, Brasil. E-mail: arturkanadani@gmail.com
}

\section{RESUMO}

\begin{abstract}
Relata-se pela primeira vez a infestação de caprinos e ovinos por pulgas e carrapatos em propriedade rural do Município de Sinop, Mato Grosso, Brasil. Após inspeção visual e tátil da superfície corporal dos animais, os espécimes coletados foram levados ao laboratório para identificação utilizando chaves específicas. As pulgas, coletadas somente nos caprinos, pertenciam à espécie Ctenocephalides felis felis. Os carrapatos coletados nos caprinos e ovinos pertenciam à espécie Rhipicephalus (Boophilus) microplus.

PALAVRAS-CHAVE: Caprinos, ovinos, Ctenocephalides felis felis, Rhipicephalus (Boophilus) microplus.
\end{abstract}

\begin{abstract}
CTENOCEPHALIDES FELIS FELIS (BOUCHÉ, 1835) AND RHIPICEPHALUS (BOOPHILUS) MICROPLUS (CANESTRINI, 1887) ONGOATS ANDSHEEPINTHEMUNICIPALITY OFSINOP, MATO GROSSO, BRAZIL. This is the first report of the infestation of goats and sheep by fleas and ticks on rural property in the municipality of Sinop, Mato Grosso, Brazil. After visual and tactile body surface inspection, specimens were taken to the laboratory for identification using specific keys. Fleas, collected only from goats, belonged to the species Ctenocephalides felis felis. Ticks collected from goats and sheep belonged to the species Rhipicephalus (Boophilus) microplus.
\end{abstract}

KEY WORDS: Goats, sheeps, Ctenocephalides felis felis, Rhipicephalus (Boophilus) microplus.

Acaprinovinocultura temsedestacadonosúltimos anos como opção de diversificação da produção, gerando oportunidades de emprego, renda e fixação do homem no campo, demonstrando importante papel no contexto da pecuária brasileira (CORREIA, 2008).

Dentre os fatores sanitários limitantes ao desenvolvimento da caprinovinocultura, destacam-se as doenças parasitárias. Segundo MAciel et al. (2006), dependendo do sistema de manejo, as ectoparasitoses podem determinar perdas significativas na criação de pequenos ruminantes, demandando maior atenção dos produtores em determinadas épocas do ano em que infestações intensas podem causar desde a redução da produtividade, em consequência do estresse gerado pelo intenso prurido provocado pela dermatite alérgica à picada e pelas infecções cutâneas secundárias, até a morte dos animais com o agravamento do quadro.

Relatos de infestação de caprinos e ovinos por pulgas e carrapatos foram feitos ao Laboratório de Parasitologia e Doenças Parasitárias de Animais
Domésticos, nos meses de setembro e outubro do ano de 2010 por estagiários de um projeto de extensão do curso de Zootecnia da Universidade Federal de Mato Grosso, Campus de Sinop.

Após o relato, visitas foram realizadas na propriedade Cabanha Cometa, Município de Sinop, onde 13 caprinos (7 fêmeas e 6 machos) mestiços Boer $\mathrm{X}$ animais sem padrão racial definido (SRD) e 22 ovinos (12 machos e 10 fêmeas), mestiços Santa Inês $x$ Texel, com idades entre 3 meses e 2 anos, foram escolhidos aleatoriamente e examinados clinicamente em busca de possíveis lesões cutâneas indicativas de ectoparasitismo. Na inspeção visual, foram encontrados pulgas e carrapatos em todos os caprinos e somente carrapatos nos ovinos. Durante a visita foram coletados também ectoparasitos de 2 cães da propriedade. Estes parasitos foram coletados manualmente e acondicionados em frascos de vidro contendo álcool etílico a 70\%.

A classificação, quanto ao gênero e espécie dos exemplares obtidos, foi realizada no Laboratório de

${ }^{2}$ Universidade Federal de Viçosa, Bioagro, Viçosa, MG, Brasil. 
Parasitologia Veterinária da Universidade Federal de Mato Grosso, Campus de Sinop, baseada nas chaves de identificação de ARAGÃo; FonseCA (1961) e LinARDi; Guimarães (2000). Dados referentes ao manejo dos animais e da propriedade foram obtidos por meio de entrevista com o técnico responsável pela propriedade.

Os exemplares de carrapato coletados tanto dos caprinos, quanto dos ovinos, pertenciam à espécie Rhipicephalus (Boophilus) microplus, enquanto que os exemplares de pulga coletados dos caprinos pertenciam à espécie Ctenocephalides felis felis. Este achado em caprinos coincide com o levantamento epidemiológico realizado por BEZERRA et al. (2010) que observaram, dentre outros parasitos, a infestação por C. felis felis e R. (B.) microplus, no Rio Grande do Norte. Já a infestação de ovinos por $R$. (B.) microplus foi relatada por MADEIRA et al. (2000) no Estado de São Paulo e Brito et al. (2005), no Maranhão.

Habitualmente, na literatura especializada, as pulgas não são incluídas como ectoparasitos de importância em caprinos e ovinos (SANTA RosA, 1996; Pugh, 2004), entretanto, é crescente o número de relatos destes ectoparasitos nestas espécies animais (KAAL et al., 2006; BEZERRA et al., 2009; BEZERRA et al., 2010; BenAVIDES ORTIZ, 2010).

Pulgas são ectoparasitos obrigatórios espécieespecíficas, porém, na ausência do hospedeiro específico e estimuladas pela necessidade de realizar a hematofagia, podem espoliar hospedeiros alternativos como bovinos, caprinos, ovinos e inclusive o homem (BENESI et al., 1998; Bicho; Ribeiro, 1998; BEZERRA et al., 2009).

Os cães inspecionados apresentavam infestação por C. felis felis e Rhipicephalus sanguineus, evidenciando, desta forma, serem a possível fonte de pulgas para a infestação ambiental e dos outros animais. Esta hipótese foi reforçada pelo relato do responsável técnico da propriedade, informando que esses cães circulavam livremente pelas instalações e piquetes em que os animais permaneciam.

As pulgas observadas encontravam-senas regiões abdomino-ventral elateral, escápulo-umeral, base da orelha e superfície da pina auricular. Os carrapatos foram encontrados na orelha externa e interna e nos membros anteriores e posteriores. Verificou-se que alguns dos animais infestados apresentavam apatia, palidez de mucosas, edema submandibular, pápulas, descamação do epitélio com prurido na região abdominal.

Rhipicephalus (Boophilus) microplus tem como hospedeiro preferencial os bovinos, contudo, em épocas de elevada infestação de pastagens, podem ser observados parasitando ovelhas, equinos, veados, caprinos e o homem (GONZALES, 1974; BITTENCOURT et al., 1990; DANTAS-TORRES, 2009).
Quadros de anemia em caprinos e ovinos podem estar relacionados a várias causas de origem parasitária, incluindo carrapatos, helmintos, piolhos, pulgas, várias espécies de dípteros e protozoários (SANTA Rosa, 1996; Pugh, 2004; Benavides Ortiz et al., 2010; TAYLOR et al., 2010). Em vários animais inspecionados, foi observada palidez da mucosa ocular, sugestiva de anemia. Este fato pode estar relacionado com a infestação por pulgas e carrapatos, entretanto, com o histórico de parasitismo por Haemonchus na propriedade, relatado durante a entrevista, é provável que a anemia seja consequência parasitismo por este helminto, tendo sido agravada pelos ectoparasitos.

No final do mês de novembro todos os animais da propriedade foram tratados com produto concentrado emulsionável à base de cipermetrina e, duas semanas após o tratamento, na inspeção visual dos animais, não foram encontrados mais ectoparasitos.

Este é o primeiro relato da infestação de caprinos e ovinos por C. felis felis e R. (B.) microplus na região Norte do Estado de Mato Grosso.

Estudos epidemiológicos são necessários para esclarecer os fatores predisponentes à infestação por pulgas e carrapatos em ovinos e caprinos, suas consequências para a produtividade e estabelecer medidas de controle mais eficazes contra ectoparasitoses em pequenos ruminantes na região deSinop, Mato Grosso.

\section{REFERÊNCIAS}

ARAGÃO, H.P.; FONSECA, F. Notas de ixodologia. VIII Lista e chave para os representantes da fauna ixodológica brasileira. Memórias do Instituto Oswaldo Cruz, v.59, p.115-129, 1961.

BENAVIDES ORTIZ, E.; MÚRCIA, N.G.; TRUJILLO, V.V.; CAMACHO, D.G.; ROZO, M.L.; CONTRERAS,A.M.S. Reporte de caso: pulicosis por Ctenocephalides felis felis en ovinos y caprinos en la sabana de Bogotá, Colombia. Revista de Medicina Veterinária, n.19, p.123-135, 2010 Disponível em: <http:// www.scielo.org.co/pdf/rmv/n19/n19a11.pdf >. Acesso em: 20 out. 2012.

BENESI, F.J.; PEREIRA, M.C.; CARDOSO DE SÁ, C.S.; HOWARD, D.L.; TEIXEIRA, C.M.C.; LARSSON, C.E. Cat flea infestation in a newborn jersey calf in Brazil. Revista Brasileira de Parasitologia Veterinária, v.7, n.2, p.157-160, 1998.

BEZERRA, A.C.D.S.; AHID, S.M. M.; VIEIRA, L.S. Ocorrência de Ctenocephalides felis felis (Bouché,1835) em caprinos no Rio Grande do Norte, Brasil. Arquivos do Instituto Biológico, São Paulo, v.76, n.3, p.459-460, 2009. Disponível em: <http://www.biologico.sp.gov.br/ docs/arq/v76_3/bezerra.pdf>. Acesso em: 20 out. 2012. 
BEZERRA A.S.; AHID, S.; VIEIRA, L.S.; SOARES, H.S. Ectoparasitos em caprinos e ovinos no município de Mossoró, Rio Grande do Norte. Ciência Animal Brasileira, v.11, p.114-120, 2010. Disponível em: <http://www.revistas.ufg.br/index.php/vet/article/ view/3800/8083>. Acesso em: 25 out. 2012.

BICHO, C.L.; RIBEIRO, P.B. Chave Pictórica para as Principais Espécies de Siphonaptera de Importância Médica e Veterinária, no Brasil. Revista Brasileira de Parasitologia Veterinária, v.7, n.1, p.47-51, 1998.

BITTENCOURT, A.J.; FONSECA, A.H.; FACCINI, J.L.H.; BUENO, B.H. Comportamento do B. microplus (Canestrini, 1887) (Acari) em infestações artificais e naturais em diferentes hospedeiros. Arquivos da Universidade Federal Rural do Rio de Janeiro, v.13, n.2, p.173-182, 1990.

BRITO, D.R.B.; SANTOS, A.C.G.; GUERRA, R.M.S.N.C. Ectoparasitos em rebanhos de caprinos e ovinos na microrregião do Alto Mearim e Grajaú, Estado do Maranhão. Revista Brasileira de Parasitologia Veterinária, v.14, n.2, p.59-63, 2005.

CORREIA, F.W.S. Perfil setorial da caprinocultura no Mundo, Brasil, Nordeste e Sergipe - Sebrae. 2008. Disponível em: <http://www.biblioteca.sebrae.com.br>. Acesso em: 21 out. 2012.

DANTAS-TORRES, F. Ticks on domestic animals in Pernambuco, northeastern Brazil. Revista Brasileira de Parasitologia Veterinária, v.18, p.22-28, 2009.

GONZALES, J.C. O carrapato do boi: vida, resistência e controle. São Paulo: Mestre Jou, 1974. 101p.
KAAL, J.F.; BAKER, K.; TORGERSON, P.R. Epidemiology of flea infestation of ruminants in Libya. Veterinary Parasitology, v.141, p.313-318, 2006.

LINARDI, P.M.; GUIMARÃES, L.R. Sifonápteros do Brasil. São Paulo: Museu de Zoologia USP/FAPESP, 2000. 291p.

MACIEL, F.C.; AHID, S.M.M.; MOREIRA, F.R.C. Manejo sanitário de caprinos e ovinos. In: LIMA, G.F.C.; HOLANDA JÚNIOR, E.V.; MACIEL, F.C.; BARROS, N.N.; AMORIM, M.V.; CONFESSOR JÚNIOR, A.A. (Org.). Criação familiar de caprinos e ovinos no Rio Grande do Norte: orientações para viabilização do negócio rural. Natal: EMATER, RN/EMPARN/EMBRAPA Caprinos, 2006. p.391-426.

MADEIRA, N.G.; AMARANTE, A.F.T.; PADOVANI, C.R. Diversity of ectoparasites in sheep flocks in São Paulo, Brazil. Tropical Animal Health and Production, v.32, n.4, p.225-232, 2000.

PUGH, D.G. Clínica de ovinos e caprinos. São Paulo: Roca, 2004. 513p.

SANTA ROSA, J. Enfermidades em caprinos: diagnóstico, patogenia, terapêutica e controle. Brasília: Embrapa-SPI: Embrapa-CNPC, 1996. 220p.

TAYLOR, M.A.; COOP, R.L.; WALL, R.L. Parasitologia veterinária. 3.ed. Rio de Janeiro: Guanabara-Koogan, 2010. 742p.

Recebido em 27/8/11

Aceito em 26/10/12 